\title{
Family Planning Use Among Women Attending a Health Care Facility in Rural Ghana
}

\author{
Adadow Yidana ${ }^{1,}$, Alhassan Salifu Sharif ${ }^{2}$ \\ ${ }^{1}$ Department of Community Health and Family Medicine, School of Medicine and Health Sciences, University for Development Studies, \\ Tamale, Ghana \\ ${ }^{2}$ Department of Public Health, School of Allied Health Sciences, University for Development Studies, Tamale, Ghana
}

Email address:

adadowy@yahoo.com (A. Yidana),assharif76@yahoo.com (A. S. Sharif)

${ }^{*}$ Corresponding author

To cite this article:

Adadow Yidana, Alhassan Salifu Sharif. Family Planning Use Among Women Attending a Health Care Facility in Rural Ghana. Central African Journal of Public Health. Vol. 4, No. 4, 2018, pp. 119-124. doi: 10.11648/j.cajph.20180404.14

Received: August 7, 2018; Accepted: August 22, 2018; Published: September 19, 2018

\begin{abstract}
Demand for and the use of family planning is fundamental in ensuring access to sexual and reproductive health care. Family planning in Ghana remains a delicate issue that is reluctantly accepted. This study was carried out to assess the use of family planning among women attending a health facility in Ghana. A descriptivecross-sectional study design was used involving 344 respondents, randomly selected for the study. A questionnairewas used in data collection and was analyzed using SPSS version 21.0. Majority of the respondents were between the ages of 25-35. Again, the majority was married; again, the majority was non-salaried workers. The majority had good knowledge of family planning, and many had used family planning services for up to 2 years. Almost $50 \%$ believed that the ideal time to use family planning services after childbirth is $1-3$ months. Many claimed family planning worked effectively for them. Again, the majority received husbands support and approval for family planning services. Barriers to family planning were affordability, religion, and health worker attitude. The study concludes that family planning usage in the study area could be improved. The study recommends awareness creation on the relevance of family planning among women within the study community.
\end{abstract}

Keywords: Family Planning, Attendance, Healthcare, Women, Rural Ghana

\section{Background}

Demand for and the use of family planning is fundamental in ensuring access to sexual and reproductive health care services [1]. Minimizing the increasing incidence of unwanted pregnancies and promoting child spacing hinges on the timely utilization of family planning service [2]. The United Nation Sustainable Development Goals' targets 3.7 and 5.6, stipulates that by the year 2030, access to reproductive health services should be universal [1]. The role family planning plays in decision making with regard to population growth and development has drawn the attention of the global community to its utilization [3]. Family planning essentially is meant to enable couples or individuals to attain the desired number of children, how and when they need them through the use of contraceptive methods [4-6]. In Ghana, however, family planning has remained a delicate issue that is still reluctantly accepted on account of religious beliefs and the misconception that family planning is synonymous with population control [7]. It must be emphasized that timely utilization of family planning intervention can contribute to healthy timing and spacing of pregnancy. Again, it plays an important role in decreasing maternal mortality [8]. The realization of the important role of family planning methods and the speed with which this knowledge was put to practice worldwide is perhaps the most remarkable achievements [9]. This notwithstanding, people in lower income economies are still battling with the rapid and uncontrolled increase in population [10]. Research shows that most unintended pregnancies result because many people in the population do not still appraciate the role of family planning in the prevention of these unwanted pregnancies [11-12].

Traditionally, women were the focus of family planning regardless of the important role played by male partners [2]. In the lower income economies, male's general knowledge and attitudes concerning the ideal family size, gender 
preference of children, ideal child spacing and contraceptive use greatly influence women's preferences and opinions on family planning [13-15]. Male partners in these economies are the primary decision-makers regarding family size and the type of family planning method to use if any [16-17]. This area of research has not been given the needed attention within the Upper East region of Ghana. The existing knowledge is information within mass media outlets and is health facility based. The total fertility rate is 4.8 births per woman and is considerably higher in the rural than the urban areas and its country-specific within the sub-Saharan region [18]. The limited use of family planning services among married women in lower income economies is attributed to inadequate knowledge, socio-economic problem, fear of side effects; religious, insufficient family planning information and services, uncooperative husbands and limited supply of family planning services and high cost of services sometimes affect the utilization [19-20]. The main objective of the study was to assess the knowledge and practice of women aged1549yearsattending the Bawku Presbyterian Hospital on family planning.

\section{Methods and Design}

Thestudy was a facility based descriptive cross-sectional design. The study was conducted between June and October 2017. The study examined the experiences of a cross-section of women attending the Bawku Presbyterian Hospital in the Upper East Region of Ghana. The study design was deemed appropriate for this study because of its potential to allow for a section of the population to be selected [21]. The study population was all women in their fertile age in the study area who attended the Bawku Presbyterian Hospital.

\subsection{Sampling}

A total of 344 respondents were sampled. The sample size was calculated using the formula, $n=z^{2} p q / d^{2}$. A simple random sampling technique was employed to select respondents. At the site, a number of women were asked to pick pieces of papers from a container after they had consented to take part in the study. These pieces of papers contained "Yes" or "No." All those who picked 'Yes' were used as respondents. This exercise was undertaken at the time the women were waiting to be attended to by health care providers.

\subsection{Data Collection and Analysis}

A structured questionnaire with both closed and openended questions was used in the data collection. An interview-administered questionnaire was used to elicit the desired information from the respondents. Due to the number of respondents involved in the study, two research assistants were engaged and given the requisite training to read and administer the questionnaire to the respondents especially those who could not read or write. The completed questionnaires were crossed checked for completeness and accuracy. The data was entered on to statistical software (SPSS, version 22.0) and then analyzed.

\subsection{Ethical Considerations}

The head of the institution where the study took place granted the researchers permission to conduct the study. Written consent was obtained from each participating woman after the purpose of study was explained to them. All the respondents were assured of anonymity and confidentiality. They were also assured of harm free and infliction free interaction. The final opportunity was given to them to decide to participate or not to participate.

\section{Results}

\subsection{Demographic Characteristics of Respondents}

Age is an important factor in maternal health. Results from the study showed that $55.9 \%$ of the respondents were between ages 25 to 34 years; $36.3 \%$ were between ages 15 to 25 years, and $7.6 \%$ were between ages 35 to 45 years (Table 1). Again, the mean age of the respondents was 22.2 (SD 2.9). Regardings their marital status, $78.2 \%$ were married whilst $18.9 \%$ were single.About $2.9 \%$ of the respondents were divorcees. The average age of marriage among the respondents was 21.1 years and the average age of first pregnancy was 22.81 years. On educational qualification, $18 \%$ had at least Senior High School education, $34.9 \%$ had at least tertiary education, $21.8 \%$ had at least Junior High School education and $13.4 \%$ had no formal educational training.

Table 1. Demographic characteristics of respondents.

\begin{tabular}{lll}
\hline Variable & Frequency & Percent (\%) \\
\hline Age (years) & & \\
$15-24$ & 127 & 36.9 \\
$25-34$ & 191 & 55.5 \\
$35-45$ & 26 & 7.6 \\
Total & 344 & 100 \\
Educational status & & \\
No formal education & 46 & 13.4 \\
Primary & 41 & 11.9 \\
Middle/JHS & 75 & 21.8 \\
SHS & 62 & 18.0 \\
Tertiary & 120 & 34.9 \\
Total & 344 & 100 \\
Marital status & & \\
Single & 65 & 18.9 \\
Married & 269 & 78.2 \\
Divorced & 10 & 2.9 \\
Total & 344 & 100 \\
Occupational status & & \\
Salaried workers & 142 & 41.3 \\
Nonsalaried workers & 202 & 58.7 \\
Total & 344 & 100 \\
Husband occupational status & & \\
Salaried worker & 144 & 20.9 \\
Farmer & 89 & 11.3 \\
Unemployed & 72 & 100 \\
Student & 39 & \\
Total & 344 & \\
\hline & & \\
\hline
\end{tabular}

Source: Field data, 2017 
Again on religious affiliation, $61.3 \%$ were Muslims whilst $36 \%$ and $2.7 \%$ were Christians and indigenous religious believers respectively. Again, $58.7 \%$ of the respondents worked in the informal sector while $41.3 \%$ were employed in the formal sector. The educational level of respondents' husbands was also assessed. About $31.1 \%$ had secondary education whilst $25.6 \%$ had no formal education. With regard to the number of children they had, $55 \%$ had $1-4$ children; $25 \%$ had $1-2$ children; $10 \%$ were evenly distributed at having 4 or more children and primigravida.

\subsection{Knowledge on Family Planning Services}

Results from the study showed that $93 \%$ had ever heard about family planning before at the time of the study. Interestingly, $7 \%$ had never heard of family planning at the time of the study. Among those who have heard of family planning, their sources of information included; schools, media, health centres, markets, relatives and friends (Figure 1). Asregards their understanding of the meaning of family planning, $83 \%$ explained family planning is used to control pregnancy whereas $14 \%$ indicated family planning is used for spacing birth. Again, 3\% were of the opinion that family planning is for preventing sexually transmitted infections (STIs) and pregnancy. Again, 32\%of the respondents had used family planning before at the time of the study whilst $68 \%$ indicated they had never used family planning services.

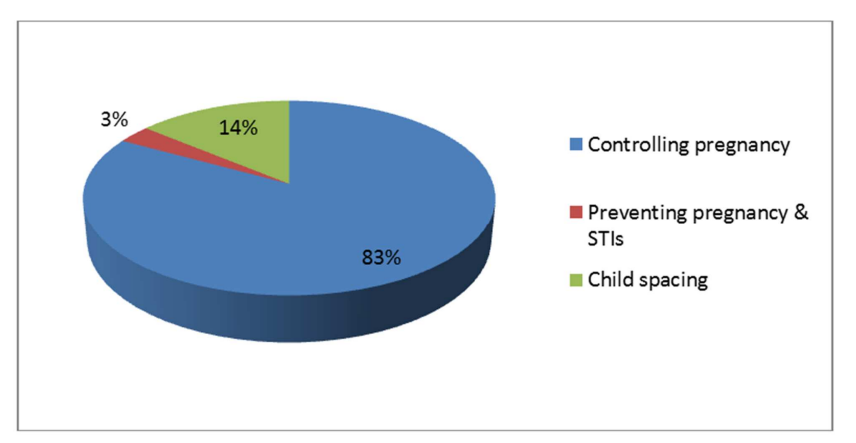

Source: Field data, 2017

Figure 1.Meaning of family planning.

\subsection{Duration of the Use of Family Planning Services}

Table 2. Duration of use of family planning services.

\begin{tabular}{lll}
\hline Variable & Frequency & Percent (\%) \\
\hline Duration of family planning & & \\
Less than 1 year & 74 & 40 \\
1-2 years & 82 & 44.3 \\
3-4 years & 20 & 10.8 \\
5 years and above & 9 & 4.9 \\
Contraceptive use after birth & & \\
Immediately & 49 & 26.5 \\
Within 1-3 months & 92 & 49.7 \\
4-5 months after birth & 44 & 23.8 \\
\hline
\end{tabular}

Source: Field data, 2017

From the study, it was revealed that $44.3 \%$ of the respondents who had used contraceptives before at the time of the study had used it between 1-2 years; $40 \%$ used it for less than a year (Table 2). Again, 26.5\% of the respondents said contraceptives could be used immediately after birth whilst $23.8 \%$ respondents said contraceptives could be used 4-5 months after birth.

\subsection{Effectiveness of Family Planning Services}

The results showed that $47 \%$ of those who had used family planning service before indicated that it was effective. Again, $13 \%$ said it was moderate (Figure 2). Again, 46.8\% said they ever heard of emergency contraceptives whereas $53.2 \%$ never heard about emergency contraceptives. Among those who had ever heard of it, they said it as any contraceptive taken immediately after having unprotected sexual intercourse to prevent pregnancy.

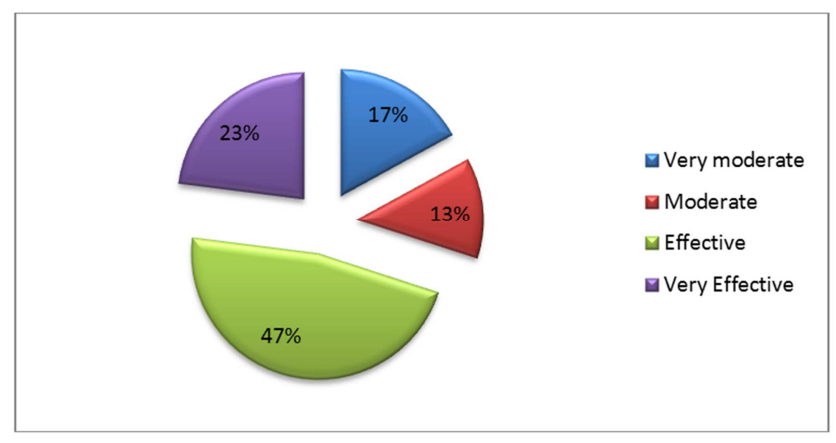

Figure 2. Effectiveness of family planning methods used. Source: Field data, 2017.

\subsection{Knowledge of Family Planning Methods}

Table 3. Family planning methods.

\begin{tabular}{lll}
\hline Variable & Yes & No \\
\hline Pills & $119(34.6 \%)$ & $225(65.4 \%)$ \\
Intrauterine device & $6(1.7 \%)$ & $338(98.3 \%)$ \\
Injectable (depo-provera) & $100(29.1 \%)$ & $244(70.9 \%)$ \\
Norplant & $46(13.4 \%)$ & $298(86.6 \%)$ \\
Condom & $101(29.4 \%)$ & $243(70.6 \%)$ \\
Spermicidal & $4(1.2 \%)$ & $340(98.8 \%)$ \\
Tubal Ligation (female) & $2(0.6 \%)$ & $342(99.4 \%)$ \\
Sterilization & $4(1.2 \%)$ & $340(98.8 \%)$ \\
Periodic abstinence/ calendar & $52(15.1 \%)$ & $292(84.9 \%)$ \\
Natural family planning methods & & \\
Withdrawal method & $137(39.8 \%)$ & $207(60.2 \%)$ \\
Calendar method & $194(56.4 \%)$ & $150(43.6 \%)$ \\
SDM & $9(2.6 \%)$ & $335(97.4 \%)$ \\
Basal temperature & $48(14.0 \%)$ & $296(86.0 \%)$ \\
Lactational amenorrhea & $78(22.7 \%)$ & $266(77.3 \%)$ \\
\hline
\end{tabular}

Source: Field data, 2017

From the results, 93\% of the respondents indicated the existence of various types of family planning methods to choose from whilst $7 \%$ said they had no idea. The family planning methods mentioned include; Pills, Intrauterine device (IUCD), Injectable (depo-provera), Norplant (buried under the skin), Condom, Spermicidal, Tubal ligation/female, Sterilization, Vasectomy/male sterilization and periodic abstinence/calendar (Table 3). From the results, 34.6\% ever used pills before whilst $65.4 \%$ said they never used it. Again, 
$1.2 \%$ ever used spermicidal before whilst $98.8 \%$ responded to the contrary. Additionally, 29.1\% claimed they had used injectable before. Again, 56.4\% said they were aware of the calendar method, $39.8 \%$ said they were aware of the withdrawal method whilst $22.7 \%$ said they were aware of lactational amenorrhea.

\subsection{Barriers to the Use of Family Planning Services}

Results from the study showed that $39 \%$ of the respondents considered socio-cultural factors as a hindrance to family planning services utilization (Table 4). The results further showed that $74.4 \%$ considered the affordability of family planning services as a barrier to its uptake. Again, $89.5 \%$ did not consider interpersonal relations of significant others' influence them in accessing family planning services. Additionally, $89.5 \%$ considered the competence of service providers as a major barrier to family planning services utilization. From the study, 50.6\% said religion was a barrier to family planning practice. Despite the divergent religious views of respondents particularly with respect to Islam and Christianity, there was still a misconception that family planning adoption among believers of both sects is a violation of their own religious beliefs and practices. The research findings revealed that the majority of the Muslim and Christian sects mentioned emphatically that their practices abhor family planning in any form and therefore do not see any reason for either supporting or practising it.

Table 4. Barriers to family planning services.

\begin{tabular}{lll}
\hline Variable & Yes & No \\
\hline Socio-cultural factors & $134(39.0 \%)$ & $210(61.0 \%)$ \\
Physical access & $134(39.0 \%)$ & $50(14.5 \%)$ \\
Hours of opening and waiting & $31(9.0 \%)$ & $313(91.0 \%)$ \\
Interpersonal relations & $36(10.5 \%)$ & $308(89.5 \%)$ \\
Affordability/cost & $256(74.4 \%)$ & $88(25.6 \%)$ \\
Competent of service provider & $308(89.5 \%)$ & $36(10.5 \%)$ \\
Religion & $174(50.6 \%)$ & $170(49.4 \%)$ \\
\hline
\end{tabular}

Source: Field data, 2017

\subsection{Male Involvement in Family Planning Services Among Women Aged (15-49) Years}

From the analyses, $65.7 \%$ said their husbands approved family planning services for them whilst $34.3 \%$ said their husbands don't approve family planning services (Figure 3 ). Again, 27\% said their husbands were not supportive towards family planning, 56\% respondents said their husbands were supportive towards family planning whilst $17 \%$ respondents said their husbands were partially supportive of family planning. Some of the respondents indicated that some of them used family planning methods secretly without the knowledge of their spouses.

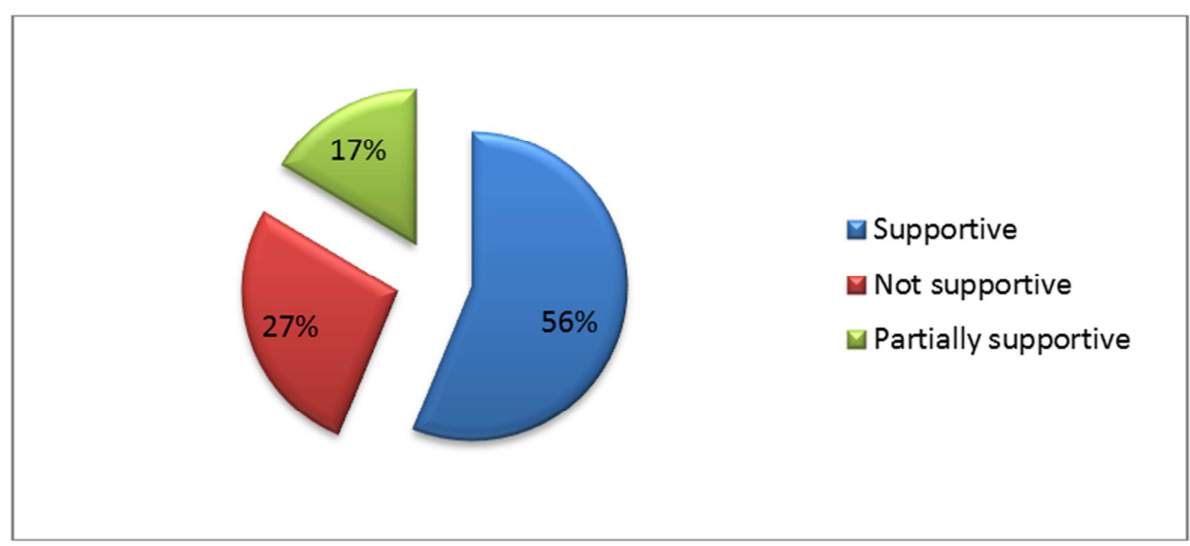

Source: Field data, 2016

Figure 3.Male position towards the use of family planning.

\section{Discussion}

Knowledge of family planning services is an important factor for an individual to consider in the use or disuse of family planning methods. In this regard, the level of knowledge has the paramount importance for policymakers and programs. It is therefore a sign of hope with $93 \%$ of respondents ever hearing of family planning before [22-25]. This is however contrary to other studies where knowledge of women about family planning was very low [26].These differences could be attributed to education. As regards the source of knowledge on family planning, the majority of the respondents identified friends, health centres, and the media among others as their main sources of information [27-28].
This may be a sign of progress with regard to information dissemination concerning family planning. It also emerged that $47 \%$ of the respondents who had ever used family planning services before indicated that it is very effective [6]. In other studies, however, results points to the contrary and respondents had to terminate usage of planning because it was not effective [29]. This difference could be attributed to the methods used, the timing of the usage and the approach.

Knowledge about the various types of family planning methods available to respondents was good, except that usage of the available methods was not encouraging. About $34.6 \%$ had ever used the pills before [30]. The study also found that $98.8 \%$ had never used spermicidal before [4]. This is however at variance with other findings where many 
women reportedly used spermicidal before [29]. Natural methods of family planning among respondents were also assessed and results indicated that $39.8 \%$ had ever used the withdrawal method as a natural family planning method [5]. This is however not consistent with a study where women indicated their husbands did not like withdrawal method [31]. It is said that some men are knowledgeable about family planning. This assertion is based on the high knowledge of men on vasectomy, injectables, pills, and IUDs as effective birth control methods [31]. The study, however, blamed men's low approval of family planning method in the matrimonial homes. Neoclassical theory suggests that an investment in human capital increases and as more women participate in the labour market, the fertility behaviour of households is bound to change, in favour of fewer children [32]. From the finding, 56.4\% of respondents had ever used the calendar method as a natural family planning method [9]. It is, however, inconsistent with findings where women did not know of the calendar method as a natural family planning method [4].

The findings again showed that $65.7 \%$ of respondent's husbands approved family planning services for them [33]. In other instance where women are not being supported, some women have fled for their lives, chased away by hostile men for using family planning. Women always wanted to use a family planning method which their husbands would not so easily notice. Such methods include injectables so that their husbands would not detect. Many women reportedly achieve this by hiding behind taking their babies for a check-up at the health facility, and then use that opportunity to get the injection. Community health workers who seek to provide family planning education and distribute contraceptives have faced hostility from men who accuse them of ruining families [34-35].

The results further revealed that $54.6 \%$ of the respondent's husbands decided everything including the number of children they should have [36]. Although both men and women have responsibilities and interest in reproductive health and family planning, demographic studies on fertility and family planning have overwhelmingly focused on women. From the results, $33.7 \%$ of the respondents had never discussed with their husbands concerning family planning methods before [37]. This may be due to the fear of been met with the hostileresponse since many husbands do not want to hear anything about family planning [38]. Women considerably have a lower social status and autonomy and this seems to be associated with their lower control over fertility.

In lower income economies, the number of people wishing to use family planning supplies and services but do not have access to modern family planning information and services still remain high [39]. Research suggests that most husbands were the only persons who could determine whether a woman should go to do family planning or not whilst a relatively smaller number said it was the decision of both the man and the woman to agree before the woman could practice family planning [22]. Lack of reproductive health services is one of the reasons for unmet needs and therefore the prevalence of unmet needs gives a clear picture of the family planning program in place.

\section{Conclusion}

The study revealed a good knowledge of respondents with regard to family planning services. The study also showed that men are supportive and also approves family planning for their wives. To sustain the use of the family planning among women, issues of affordability, religious related issues and attitude of healthcare staff may have to be addressed. The decision to use or not is primarily influenced by others from within the social network, whose views and perceptions are often more important than an individual's own. Therefore, family planning campaigns should look beyond the individual woman to include other significant social networks in order to drive demand and remove barriers affecting the uptake of family planning among women.

\section{Conflict of Interest}

All the authors do not have any possible conflict of interest.

\section{References}

[1] S'anchez-P'aez, D.A. \&Ortega, J.A. (2018). Adolescent contraceptive use and its effects on fertility, Demographic Research, 38 (45): 1359-1388.

[2] Tamiso, A., Admasu, T., Henok, B., Zale, Z., \& Admasu, D. (2016). Barriers to male involvement in family planning services in Arba Minch Town, Southern Ethiopia: Qualitative case study, International Journal of Public Health Services, 5(1): 46-50.

[3] Madhukumar, S. \& Pavithra, M. (2015). A study about perceptions, attitude, and knowledge among men toward vasectomy in Bangalore rural population, Int J Med Sci Public Health, 4(8):69-70.

[4] Obare, F. Keesbury, W. \& Liambila, A. (2010). The provision of emergency contraceptives in private sector pharmacies in urban Kenya: Experiences of mystery clients, African Population Studies, 24 (1).

[5] Nuruzzaman, H. (2010). Unmet Need for Contraceptive: The Case of Married Adolescent Women in Bangladesh, International Journal of Current Research, 9:29-31.

[6] Odimegwu, C. O. (2013). Determinants of choice of traditional and modern methods of contraception, unpublished manuscript, Department of Demography and Social Statistics, Obafemi Awolowo University, Ile-Ife, Nigeria, 23.

[7] Nketiah-Amponsah, E. Arthur, E. \& Abuosi, A. (2012). Correlates of Contraceptive use Among Ghanaian women of Reproductive Age (15-49 Years), African Journal of reproductivehealth 16 (3).

[8] Vouking, M.Z., Christine, D.E., \& Carine, N.T. (2014). Male involvement in family Planningdecision making in subSaharan Africa - what the evidence suggests, PanAfrican Medical Journal, 1-5. 
[9] Najafi, F., Rahman, H., \& Juni, M. (2011). Barriers to Modern contraceptive practices among selected married women in a public university in Malaysia, Global Journal of Health Science,3(2): 50.56.

[10] Mistik, S., Nacar, M., Mazicioglu, M. \& Centinkaya, F. (2003). Married men's opinions and involvement regarding family planning in rural areas, Contraception, 67: 133-137.

[11] Odimegwu, C. O. (2013). Family planning attitude and use in Nigeria: a factor analysis, Family planning perspective, 25: 89-91.

[12] Belay, A.B., Zelalem, B.M., Manay, K.W., \& Yalemzewod, A.G. (2016). Married women's decision making power on family planning use and associated factors in Mizan-Aman, South Ethiopia: a cross-sectional study, BMC women's' Health, doi.org/10.1186/s12905-016-0290-x.

[13] Jaya, J. \& Hindin, M. (2012). Premarital romantic partnerships: Attitudes and sexual experiences of youth in Delhi, India. International Perspectives on Sexual and Reproductive Health, 35: 102-105.

[14] Kulczycki A. (2008) Husband-wife agreement, power relations and contraceptive use in Turkey, International Family Planning Perspective34:127-37.

[15] Adegbola, O. \& Okunowo, A. (2009) Intended postpartum contraceptiveuse among Pregnantand puerperal women at a University Teaching Hospital, Arch GynecolObstet,280:98792.

[16] Nzioka, C. (2001). Research on men and its implications on policy and program development in reproductive health, in programming for male involvement in reproductive health, WHO regional advisors in reproductive health report, WHO/PAHO, Washington DC.

[17] Neville, H. \& Golden, K. (2010). Emergency contraception: Pediatricians' knowledge, attitudes, and opinions, Pediatrics, 107 (2): 287-292.

[18] Rajaretnam, T. \& Deshpande, R. (2014). Factors inhibiting the use of reversible Contraceptive methods in rural south India, Studies in Family Planning, 25(2):11-13.

[19] Tuladhar, H. \& Marahatta, R. (2010). Awareness and Practice of Family Planning methods in women attending Gynecology OPD at Nepal Medical College Teaching Hospital, Nepal Med Coll Journal, 10(3): 184-91.

[20] Schoenmarkers, R. (2013). The child spacing tradition and postpartum tab taboo in Africananthropological evidence. New York: Academic Press.

[21] Creswell, J. W. (2005). Educational research: Planning, conducting and evaluating quantitative and qualitative research (2nd ed.),Upper Saddle River, NJ: Prentice-Hall.

[22] World Health Organisation (2012). Essential contraceptives Care: A report of Technical Working Group. Geneva.

[23] Tajure, N. \& Pharm, B. (2010).Knowledge, attitude, and practice of emergency Contraception among graduating female students of Jimma University, Southwest Ethiopia, Ethiop J Health Sci. 20 (2): 91-9.

[24] Aryeetey, R. \&Hindin, M. (2010). Knowledge, Perceptions and Ever Use of Modern Contraception among Women in the
Ga East District, Ghana, African Journal of Reproductive Health, 14: 29-32.

[25] Bhattarai, D. \& Panta, O. (2013). Knowledge attitude and practice on contraception in village women in Khotang, Journal of Nepal Health Research Council. 11 (23):40-43.

[26] Rutenberg, N. (2013). Knowledge and use of contraceptive, DHS comparative studies, 6(1):67.

[27] Parr, N. (2013). Discontinuation of Contraceptive Use in Ghana, Journal of Health, Population and Nutrition, 21:5052 .

[28] Beekle, A. \& McCabe, C. (2013). Awareness and determinants of family planning practice in Jimma, Ethiopia. International Nursing Review, 53: 69-72.

[29] Olakojo, O. A. (2012). Knowledge, attitude, and practices of married women in Nigeria towards family planning, Journal of Sociology, Psychology and Anthropology in practice, 3 (4): 44.

[30] Sonenstein, F. (2011). Sex and contraception among adolescent males, The Networks,29(3):13-15.

[31] Ogunjuyigbe, A. (2013). Spousal communication, changes in partner attitude and contraceptive use among the Yoruba's of southwest Nigeria, Department of Demography and Social Statistics, Obafemi Awolowo University, Ile-Ife, Nigeria, 23.

[32] Sterley, K. (2011). Incidence of abortion worldwide: Word Health Statistics, 3(1): 22-36.

[33] Chapagain, M. (2013). Masculine Interest behind High Prevalence of Female Contraceptive Methods in Rural Nepal, Australian Journal of Rural Health, 13:35-42.

[34] Rao, G. \& Sinha, R. (2011). Male participation in family planning, An evaluation study of no-scalpel vasectomy project, Madhya Pradesh, International Institute for Population Sciences, 6: 47.

[35] Rimal, G. (2013). Knowledge, Attitude and Use of Contraceptive among currently married: Acase study of Tamang community in Samari VDC of Nuwakot District, in Central Department of Population Studies, Tribhuvan University: Kathmandu, 23.

[36] Bawah, A. Akweongo, P. \& Phillips, J. (2010). Women's Fears and Men's Anxieties: The Impact of Family Planning on Gender Relations in Northern Ghana, Studies in Family Planning,30: 59-62.

[37] Bawah, A. Simmons, R. \& Phillips, J. (2013). Women's Fears and Men's Anxieties: The Impact of Family Planning on Gender Relations in Northern Ghana, Studies in Family Planning, Vol. 30: 58-60.

[38] Gonie, A., Alemayehu, W., Dejene, N., \& Zelalem, D. (2018). Determinants of family planning use among married women in bale eco-region, Southern Ethiopia: a communitybasedstudy, Women Health, 1-10, doi.org/10.1186/s12905018-0539-7.

[39] World Health Organization (2015). Family planning/contraception: Facts Sheet. Geneva: WHO Int. publication. 